\title{
Determinação do sexo em pintos da raça Rhode Island Red *
}

\author{
WALTER RAMOS JARDIM (***)
}

Livre-Docente da 14a Cadeira da Escola Superior de Agricultura "Luiz de Queiroz". da Universidade de São Paulo

\section{INDICE}

Introdução

380

Material e Método

381

Discussão 385

Resumo e Conclusōes 386
Abstract ............. 887

Bibliografia .......... 388

Agradecimento ......... 988

( *) Trabalho da Seção de Avicultura e Cunicultura

(**) Diretor Geral do Departamento da Produçáo Animal. 


\section{INTRODUÇAOO}

A distinção do sexo em pintos de um dia vem apaixonando técnicos e avicultores há já alguns lustros. Em 1933, os japonêses MAUSI e HASHIMOTO (1) relataram o modo de se distinguir o sexo pelo exame dos órgãos copulatórios rudimentares. Cruzamentos envolvendo caractéres ligados ao sexo são também usados para o mesmo fim. A raça Cambar, por exemplo, criada por PUNNETT e PEASE, permite a distinçăo de machos e fêmeas ao nascer, pela penugem.

Há necessidade, contudo, de se descobrirem ou desenvolverem, nas raças mais comuns, caractéres externos por meio dos quais o sexo possa ser determinado precocemente, pois o método japonês requer muita prática e requisitos especiais do operador, enquanto os cruzamentas exigem a manutençáo de dois rebanhos em estado de pureza.

A raça Rhode Island Red, objeto do presente trabalho e hoje grandemente popular nas Américas, foi estudada por BYERLY e QUINN (2), em 1936. Estes investigadores, examinando o dimorfismo sexual na côr da penugem de pintos de um dia, verificaram o seguinte :

"Entre 1.102 pintos ou embriסes com 18 ou mais dias examinados, 524 ou $47,5 \%$ tinham algum prêto na penugem da cabeça. Dos pintos listados ou manchados 445 ou $84,9 \%$ eram fémeas, enquanto que 450 ou $\mathbf{7 7 , 8 \%}$ dos năo listados ou manchados eram machos. No total, o sexo fol determinado por meio das manchas ou listas em 895 ou $\mathbf{8 1 , 2 \%}$ dos pintos e embrióes examinados".

HAYS (3), em 1940, estudando 8.713 pintos selecionados para a produção de ovos verificou o que se segue quanto à relação entre a pigmentação da penugem, o sexo e a côr do adulto :

"Dos pintos machos, sòmente 10\% mostravam algumas manchas coloridas na penugem, em comparação com cêrca de $44 \%$ das fêmeas, que mostravam manchas ou listas. Na populaçáo total, 26,76\% dos pintos tinham manchas ou listas na penugem".

"Nos machos, 4,47\% apresentavam áreas pigmentadas de preto e 5,66\% áreas marrons; nas fêmeas, $27,53 \%$ com áreas pretas e $16,62 \%$ marrons".

"O tipo predominante de área pigmentada era uma mancha na cabeça. Na populaçáo com penugem pigmentada, o pre- 
to mostrou-se confinado à cabeça tanto nos machos como nas fêmeas. Manchas marrons são levemente mais comuns nos machos, em se tratando da população pigmentada. Nos pintos listados, a côr do pigmento é predominantemente preta".

"Considerando somente a população pigmentada, cerca de $15 \%$ dos pintos com pigmentos pretos eram machos e aproximadamente $26 \%$ dos que possuiam pigmentos marrons eram fêmeas".

Conclui HAYS afirmando que a côr da penugem năo tem valor comercial como indicador do sexo nas aves estudadas.

HAYS e KLEIN (4), em 1943, divulgaram um método melhorado para a identificação do sexo em pintrs Rhode Island Red, método êste descoberto por um avicultor americano. Consiste no exame da côr da penugem do dorso, do bordo anterior das asas e da cabeça. As fêmeas em geral têm a superficie dorsal uniformemente vermelha, os bordos das asas vermelhos e a cabeça vermelha, às vezes com manchas pretas; os machós mostram a superfície dorsal com áreas brancas e vermelhas, podendo ter dorso vermelho e cabeça branca, suas asas possuem bordo anterior branco ou listas brancas, e a cabeça é vermelha ou branca, desprovida de manchas pretas. Graças a estes caracteres, o sexo foi corretamente identificado em aproximadamente $80 \%$ dos pintos examinados.

Considerando apenas a côr das asas, JAAP (5), em 1946, conseguiu, examinando 216 pintos de uma linhagem da Oklahoma Agricultural Experiment Station, identificar o sexo com um acêrto de 92,6\%. Após selecionar e multiplicar machos e fémeas da referida linhagem, dentre os que mais se distinguiam pelo dimorfismo sexual acusado pela cor da penugem, alcançou, em 315 pintos, 94,9\% de identificaçăo correta. este método, por sua simplicidade e gráu de exaçăo, para a raça Rhode Island Red, é bem superior ao Japones, cujo acerto gira em tôrno de $90 \%$.

Baseado nos trabalhos citados e considerando ainda outros caractéres năo apontados na bibliografia sobre o assunto, após cuidadosas observações chegámos aos resultados que mencionamos no presente trabalho.

\section{MATERIAL E METODO}

Trabalhámos com pintos provenientes do rebanho da Escola Superior de Agriculiura "Luiz de Queiroz", stlecionado apenas pela postura, vigor e manutençăo do padrăo. Pintos de 
diversas incubações, num total de 201, foram examinados e descritos, considerando-se os seguintes caracteres : côr do bordo da asa, côr do anel da perna, côr da cabeça, côr da face ventral, cór da ponta da asa, côr da face, sinal no ângulo posterior do olho, côr do dorso, côr geral, emplumagem, tamanho da cabeça.

A côr do bordo da asa varia do branco ao creme e é observada pelo contraste com a restante penugem da regiăo ou com a coloração geral. Também variam a localizaçăo e o tamanho das manchas no bordo da asa : desde um simples traço a uma extensa e larga zona (fig. 1. A,B,C,D,E). As vezes apenas um reflexo é perceptivel.

O anel da perna, que se observa logo acima da regiáo tiblo-társica varia igualmente em coloração, forma e extensão (Fig. 2. B,C,D).

Quanto à pigmentaçăo da cabeça, verificámos apenas a presença ou năo de pintas ou manchas, sem preocupação da cór que naturalmente varia do marron ao preto.

A cór do ventre, da ponta da asa e da face fol classificada, conforme a sua intensidade, em clara e escura.

Junto ao angulo pasterior do olho, observamos a presença ou ausencia de um ponto ou traço pigmentado (Fig. 3).

Também a pigmentaçăo do dorso, sob a forma de ponto ou lista, marron ou preto, foi objeto de observaçăo.

Considerámos igualmente a côr geral da penugem, variável do amarelo ao pardo, passando pelo camurça.

Ainda mais, a emplumagem das asas fol classificada em pequena, média e grande, de acordo com o desenvolvimento apresentado.

Finalmente, o volume da cabeça fol observado e dividido em tres categorias.

No quadro que se segue, encontra-se o resultado das observaçóes feitas, considerados isoladamente os caractéres menclonados e após comprovaçáo do sexo. 

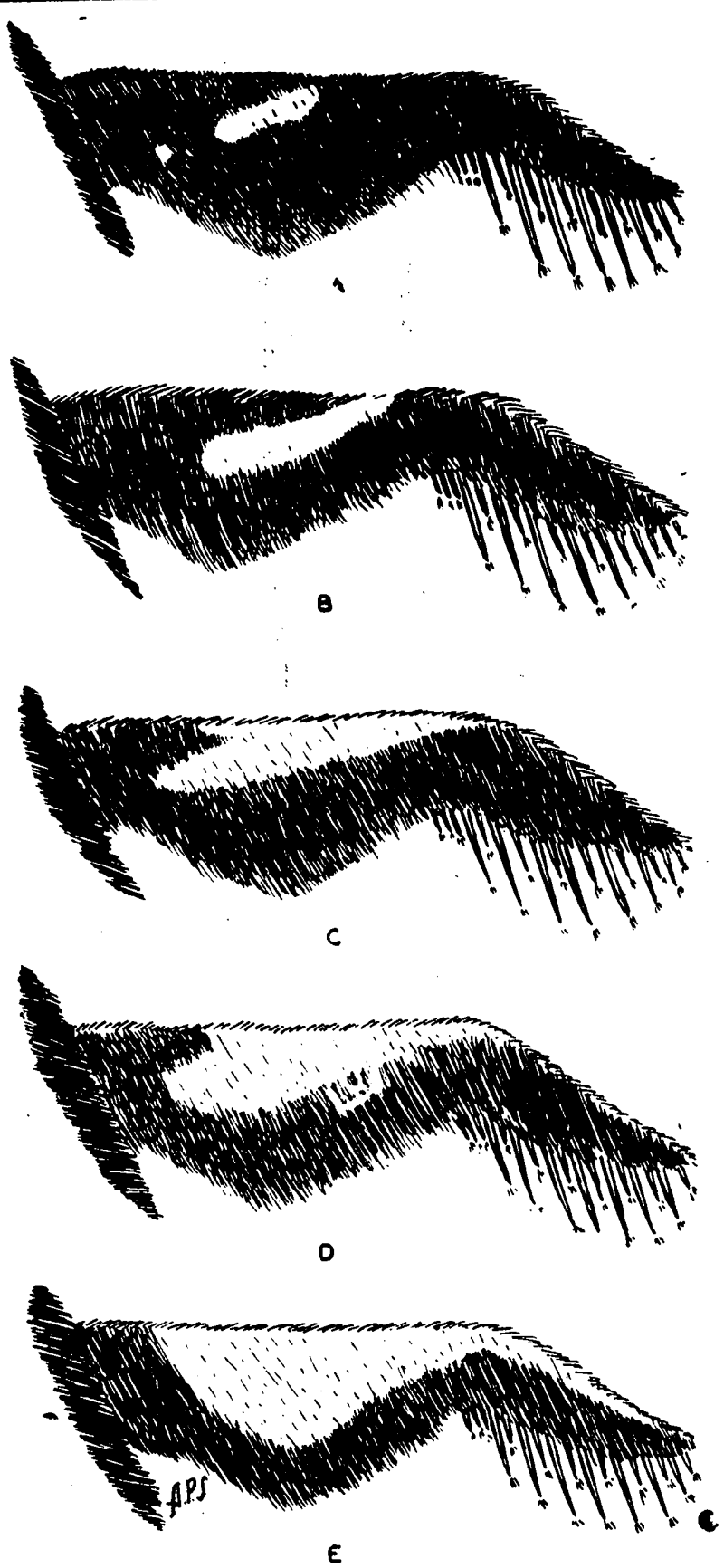

Fig. 1 - Mancha clara da asa (JAAP). 


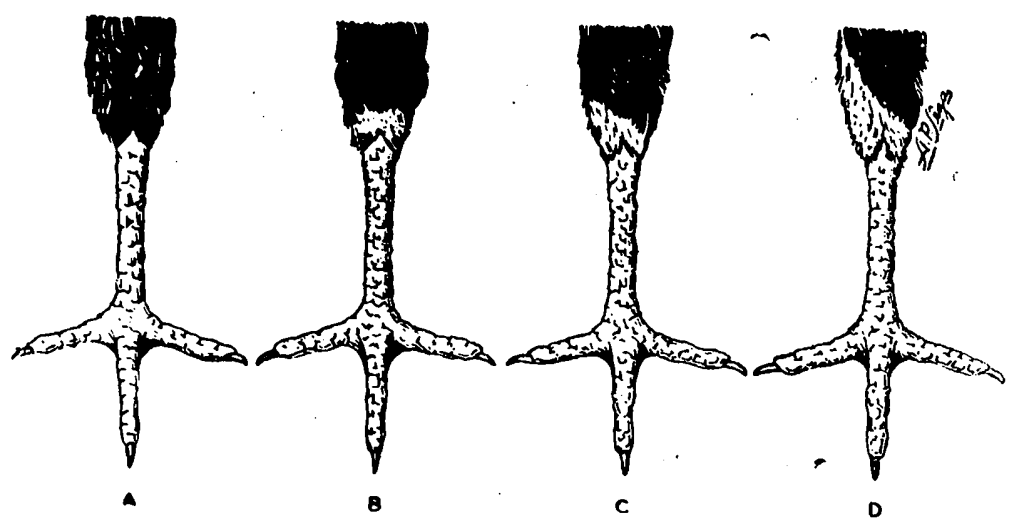

Fig. 2 - A, ausência do anel claro na perna; B, C e D, anel apresentando forma e extensão variáveis.

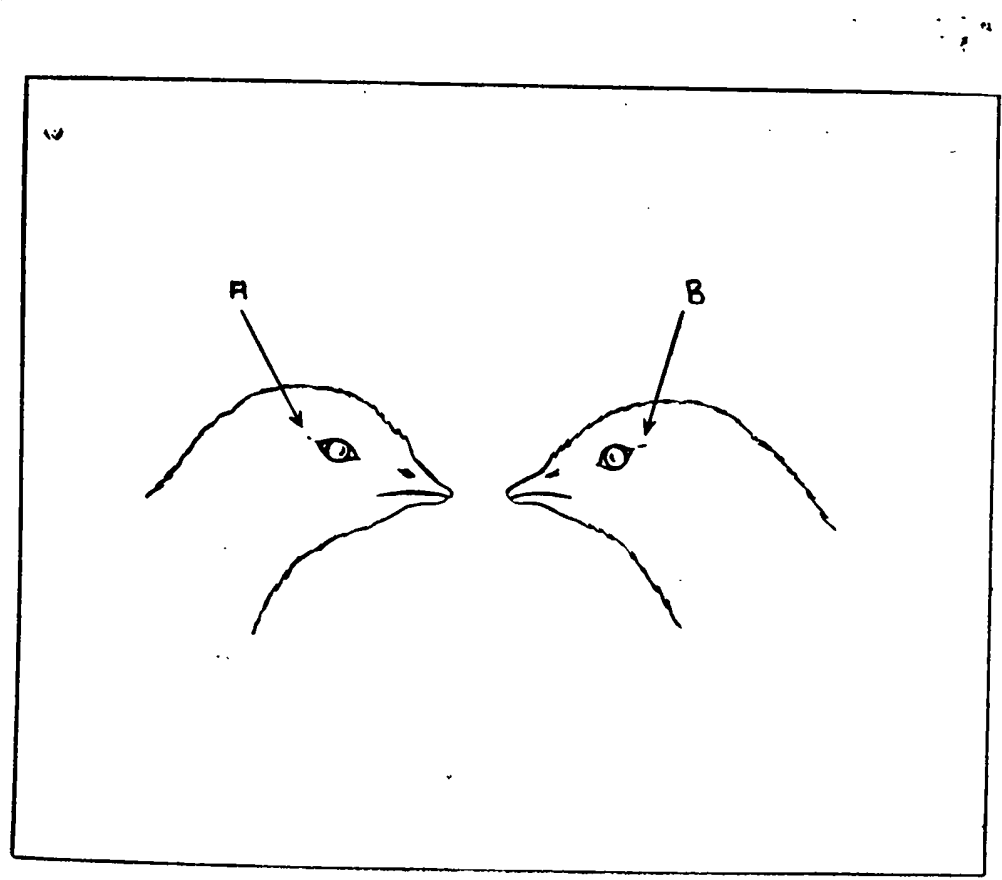

Fig. 3 - A, ponto escuro junto ao 6 lho $-\mathrm{B}$, traço escuro. 


\begin{tabular}{|c|c|c|}
\hline & $\begin{array}{c}\delta \\
\%\end{array}$ & $\begin{array}{c}P Q \\
\%\end{array}$ \\
\hline Com mancha clara na asa $\ldots \ldots \ldots \ldots \ldots \ldots$ & 100.00 & 6.30 \\
\hline Sem mancha clara na asa $\ldots \ldots \ldots \ldots \ldots \ldots$ & 0.00 & 93.70 \\
\hline Com anel claro na perna $\ldots \ldots \ldots \ldots \ldots \ldots$ & 91.80 & 3.70 \\
\hline Sem anel claro na perna $\ldots \ldots \ldots \ldots \ldots \ldots$ & 8.20 & 96.30 \\
\hline Com pinta escura na cabeça $\ldots \ldots \ldots \ldots \ldots$ & 13.10 & 87.30 \\
\hline Sem pinta escura na cabeça $\ldots \ldots \ldots \ldots \ldots$ & 86.90 & 12.70 \\
\hline 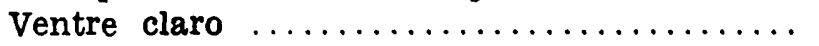 & 52.40 & \\
\hline Ventre escuro $\ldots \ldots \ldots \ldots$ & 47.60 & 76 \\
\hline Ponta da asa clara. & 100.00 & 46.80 \\
\hline Ponta da asa escura & 0.00 & \\
\hline 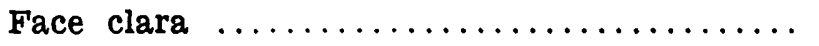 & 65.50 & \\
\hline Face escura $\ldots \ldots \ldots \ldots \ldots \ldots \ldots \ldots \ldots \ldots \ldots \ldots \ldots$ & 34.50 & \\
\hline Com sinal no angulo posterior do ôlho ...... & 4.90 & \\
\hline Sem sinal no ângulo posterior do ôlho ...... & 95.10 & 63.30 \\
\hline Com pinta sóbre o dorso $\ldots \ldots \ldots \ldots \ldots \ldots$ & 0.80 & \\
\hline 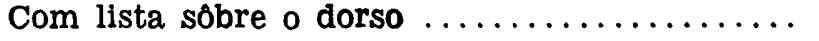 & 1,60 & \\
\hline Cór geral amarela $\ldots \ldots \ldots \ldots \ldots \ldots \ldots$ & 4.00 & \\
\hline Côr geral camurça $\ldots \ldots \ldots \ldots \ldots \ldots$ & 4.90 & \\
\hline Côr geral parda $\ldots \ldots \ldots \ldots \ldots \ldots \ldots \ldots \ldots$ & 90.90 & 89.80 \\
\hline Emplumagem pequena $\ldots \ldots \ldots \ldots \ldots \ldots$ & 42.60 & 20. \\
\hline Emplumagem média $\ldots \ldots \ldots \ldots \ldots \ldots$ & 32.70 & \\
\hline Emplumagem grande $\ldots \ldots \ldots \ldots \ldots \ldots \ldots$ & 24.50 & 39. \\
\hline Cabeça pequena $\ldots$ & 13.90 & \\
\hline 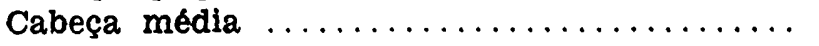 & 58.10 & \\
\hline Cabeça grande $\ldots \ldots \ldots \ldots \ldots \ldots \ldots \ldots \ldots$ & 27.80 & \\
\hline
\end{tabular}

\section{DISCUSSAO}

Considerando os caractéres acima mencionados, isoladamente e em conjunto, conseguimos em 201 pintos examinados, determinar o sexo acertadamente em 197, isto é, em 98,01\% do total, resultado êste ainda năo mencionado na mais moderna bibliografia sóbre o assunto, nem mesmo em se tratando de linhagens especialmente selecionadas para tal fim.

Como $100 \%$ dos machos apresentaram manchas claras na asa e apenas $3,7 \%$ das fêmeas mostraram anel claro na perna, temos nestes caracteres a chave principal do resultado obtido. Assim como a mancha na asa constitui o principal caráter para a identificaçáo do macho, a ausencia do anel é o mais importante para caracterizar a fêmea. Constitui, também, 
caráter interessante, o sinal no ângulo posterior do ólho, ausente em 95,1 dos machos e presente em 36,7 das fêmeas.

A cór da ponta da asa é, igualmente, elemento auxiliar valioso, pois nåo se observou ponta da asa escura em um macho sequer, mas em $53,2 \%$ das fêmeas. O caráter côr clara na ponta da asa foi notado em $100 \%$ dos machos mas, tomado isoladamente, poderá permitir confusóes, porque ocorreu em $46,8 \%$ das fêmeas.

A presença ou ausência da pinta na cabeça, assim como a coloraçăo do ventre, săo finalmente elementos dignos de exame, como se pode verificar fàcilmente, pois as pintas e ventre escuro, são bem mais frequentes nas femeas.

Outros caracteres menos valiosos, mas que as vezes podem resolver casos de dúvida, săo os seguintes: pinta e lista sóbre o dorso, nas fêmeas; côr geral camurça, nos machos; emplumagem pequena nos machos e grande nas femeas; cabeça pequena nas femeas e grande nos machos, face clara nos machos e escura nas femeas.

O padráo comum da femea é o seguinte: sem mancha na asa, sem anel na perna, com pinta escura na cabeça, sinal no ângulo posterior do olho, ponta da asa e ventre escuros.

O macho típico apresenta : mancha na asa, anel claro na perna, ausência de pinta na cabeça e de sinal no ángulo posterior do olho, ponta da asa e ventre claros.

Examinando 201 pintos de um dia, 122 machos e 79 fêmeas, errámos na determinaçáo do sexo de 4 individuos, mas mesmo assim conseguimos acertar na elevada proporçáo df 98,01\%. Em todos os casos de êrro demos mais importáncia à pinta preta na cabeça que no anel claro da perna e a mancha no bordo da asa.

Julgamos que, com alguma prática, qualquer observador atento poderá, considerando os caracteres apontados, separar, pelo sexo, pintos de um dia da raça Rhode Island Red com segurança quase absoluta. Mediante a seleçăo pelo dimorfismo sexual acusado na penugem, será dificilimo qualquer êrro.

\section{RESUMO E CONCLUSOES}

Examinando 201 pintos de um dia da raça Rhode Island Red, de rebanho selecionado pela postura e considerando diversos caracteres, principalmente os relacionados com a cór 
aa penugem, conseguimos acertar em 197, numa proporção de $98.01 \%$, não relatada da bibliografia que conhecemos.

Julgamos como mais importantes, os seguintes caracteres: mancha clara na asa notada em $100 \%$ dos machos e $6,30 \%$ das fêmeas; o anel claro na perna ocorreu em $91,80 \%$ dos machos e 3,70\% das fêmeas. Estas duas particularidades, sòmente, permitem separação de sexo superior a $96 \%$. O sinal junto ao ângulo pasterior do ôlho foi observado em 95,10\% das fémeas e $36,70 \%$ dos machos; ponta da asa escura não ocorreu em. um macho sequer; mas em $53.20 \%$ das fêmeas; ponta da asa clara foi notada em tódos os machos e em $46,80 \%$ das fêmeas.

Os demais caracteres mencionados no quadro, constituem elementos auxiliares de menor valor mas devem ser examinados para se esclarecerem dúvidas.

Os erros decorreram de se dar mais importância a pinta escura na cabeça que ao anel claro na perna e à mancha no bordo da asa.

O presente trabalho contribui para o esclarecimento do assunto principalmente por considerar o anel claro da perna e o sinal escuro próximo ao ângulo posterior do ôlho, caracteres valiosos e ainda não apontados anteriormente.

Ainda mais, a observação metódica e conjunta de um grande número de atributos relacionados com o dimorfismo sexual constitui um subsídio ao esclarecimento de tão interessante questão.

\section{ABSTRACT}

This paper refers to sex differentiation in one day chicks of the Rhode Island Red Breed, which has been selected by the laying capacity in the flock pertaining to the Escola Superior de Agricultura "Luiz de Queiroz".

The A., taking as a basis the light staining of the anterior edge of the wing, the fair ring of down of the chick leg, immediately a bove the tibiotarsic joint, and dark spot that occurs sometimes near the posterior angle of the eye, besides other characters of minor importance, was able to separate correctly 197 out of 201 chicks, what represents $98,01 \%$ of the total number. 


\section{BIBLIOGRAFIA}

1 - GIBBS, C. S. - 1944 - A guide to Sexing Chicks - Orange Judd Publishing Company, Inc.

2 - BYERLY, T. C. e QUINN, J. P. - Sexual Domorfism in Single Comb Rhode Island Red Down Color - Journal Heredity. $27: 319-322$.

3 - HAYS, F. A. - Color Markings in Rhode Island Red Chicks as Related to Sex and Adult Color - Journal of Agricultural Research. Vol. 61, n. ${ }^{\circ}$ 1. 69-74.

4 - JAAP, R. G. - Sex Identification in Baby Chicks of "Red" Varieties - Poultry Science. March 1946, Vol. XXV, n.o 2, Pag. 185.

5 - JAAP, R. G. - Wing - Spot Method Simplifies Sexing of Rhode Island Reds and New Hampshires - Poultry Review. July, 1946, Vol. 70, n.0 7, Pags. 4-5.

\section{AGRADECIMENTO}

O Autor agradece aos Snrs. Nelson S. Rodrigues e Alvaro P. Sega as fotografias e desenhos apresentados neste trabalho e ao prof. A. P. Torres pelas sugestões apresentadas. 


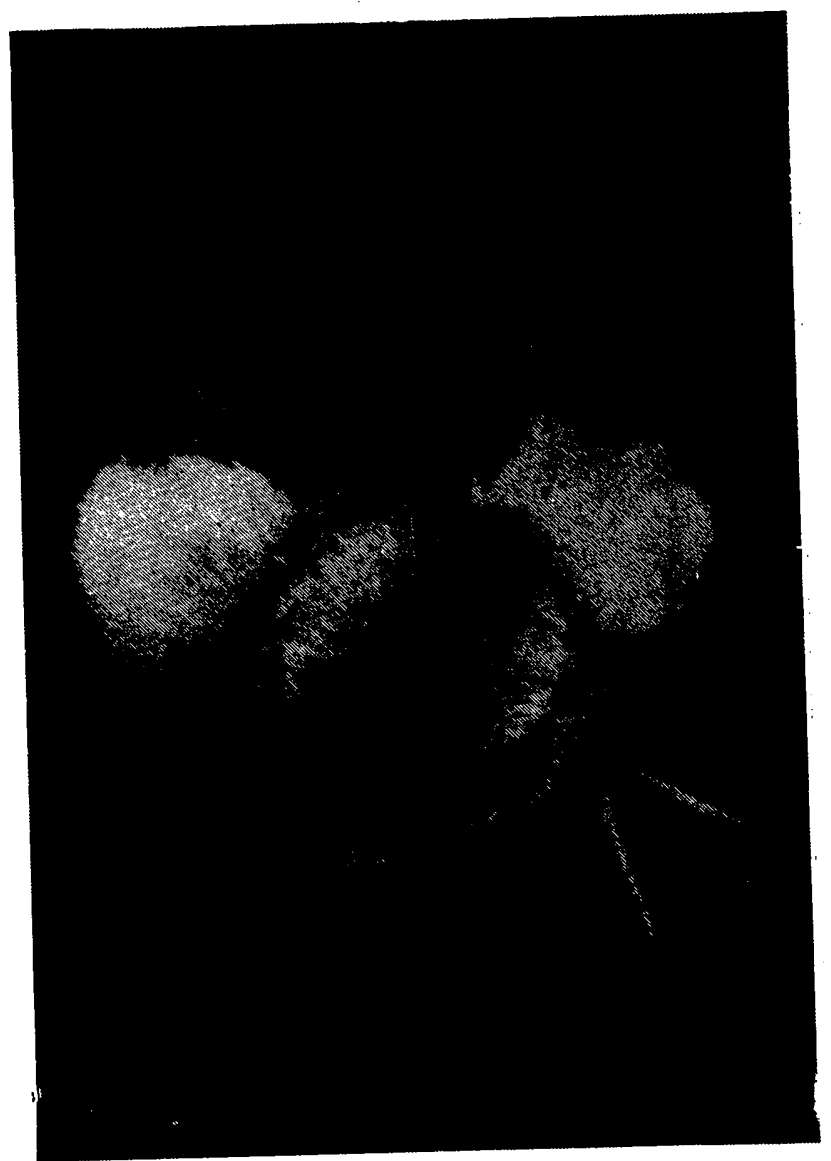

Fig. 4 - Macho típico 


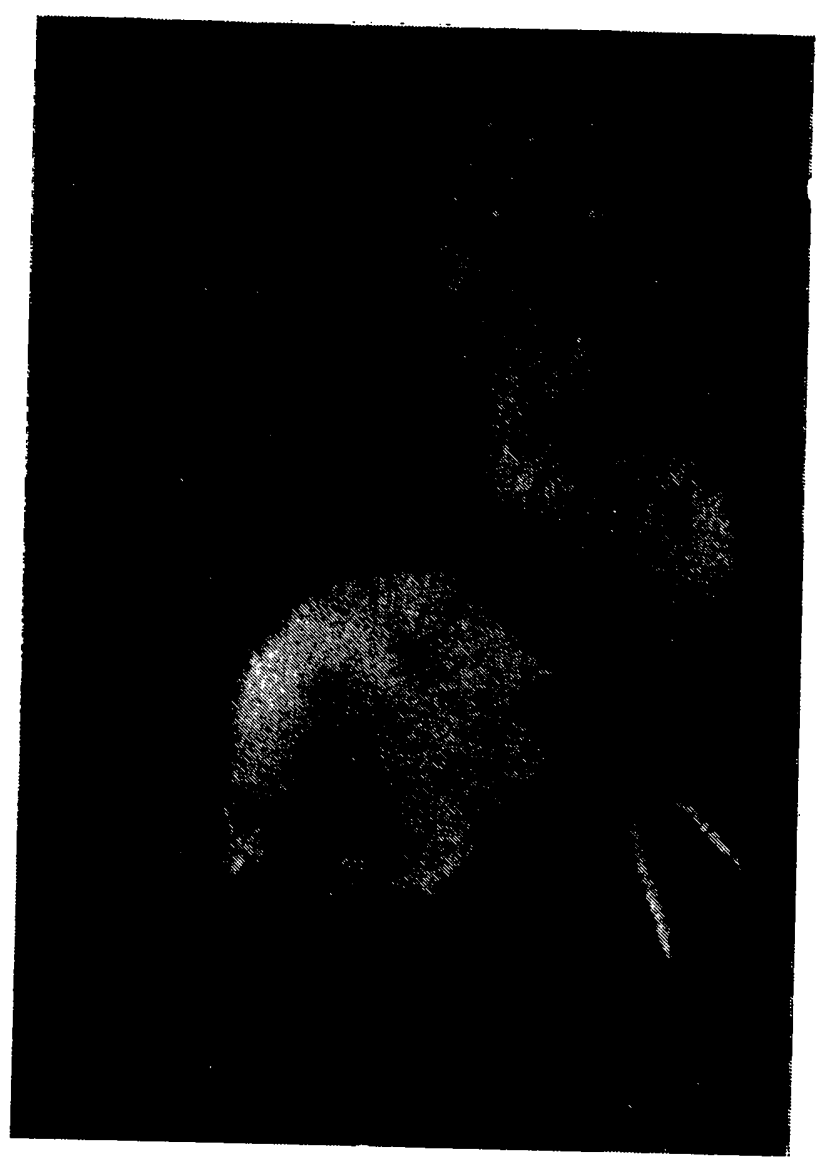

Fig. 5 - Fêmea típica. Note-se o traço escuro junto ao ôlho 


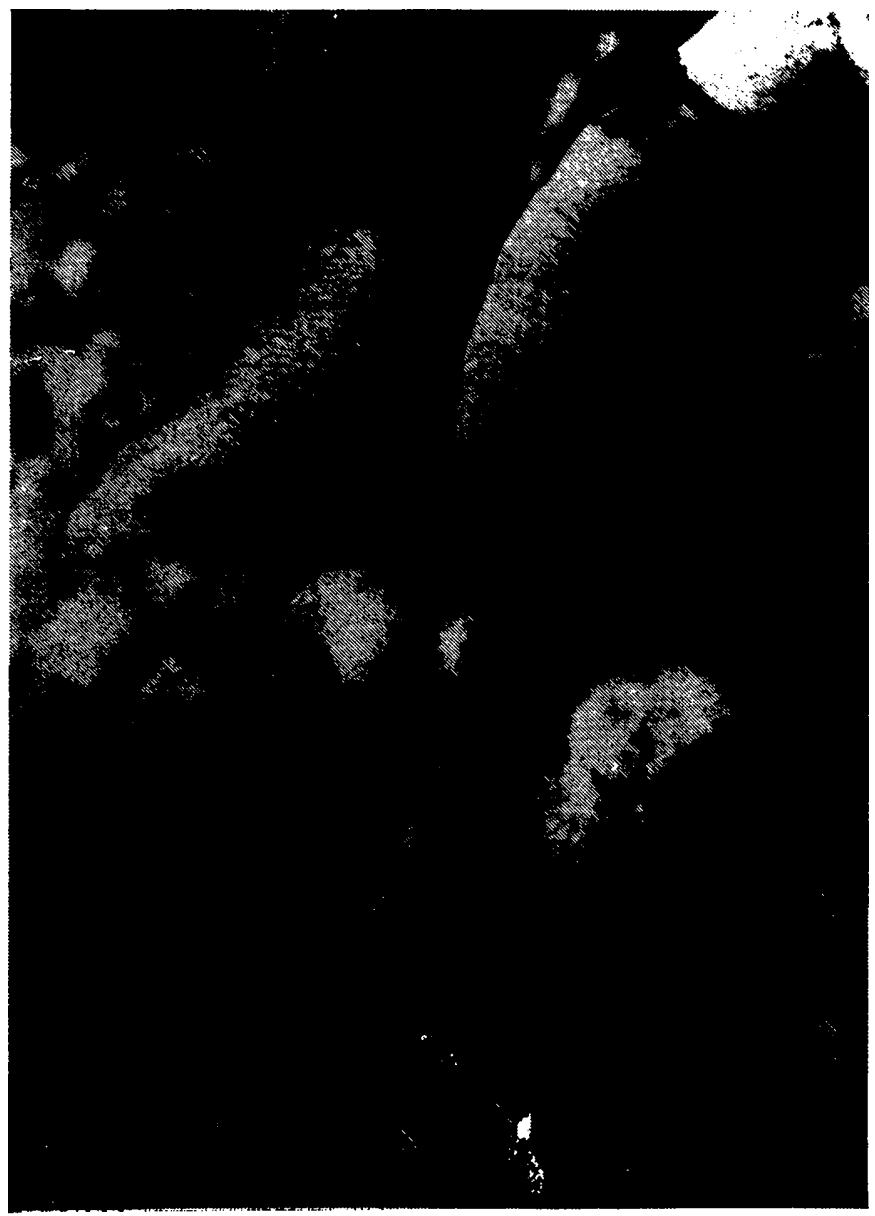

Fig. 6 - A, macho; B, fêmea. 


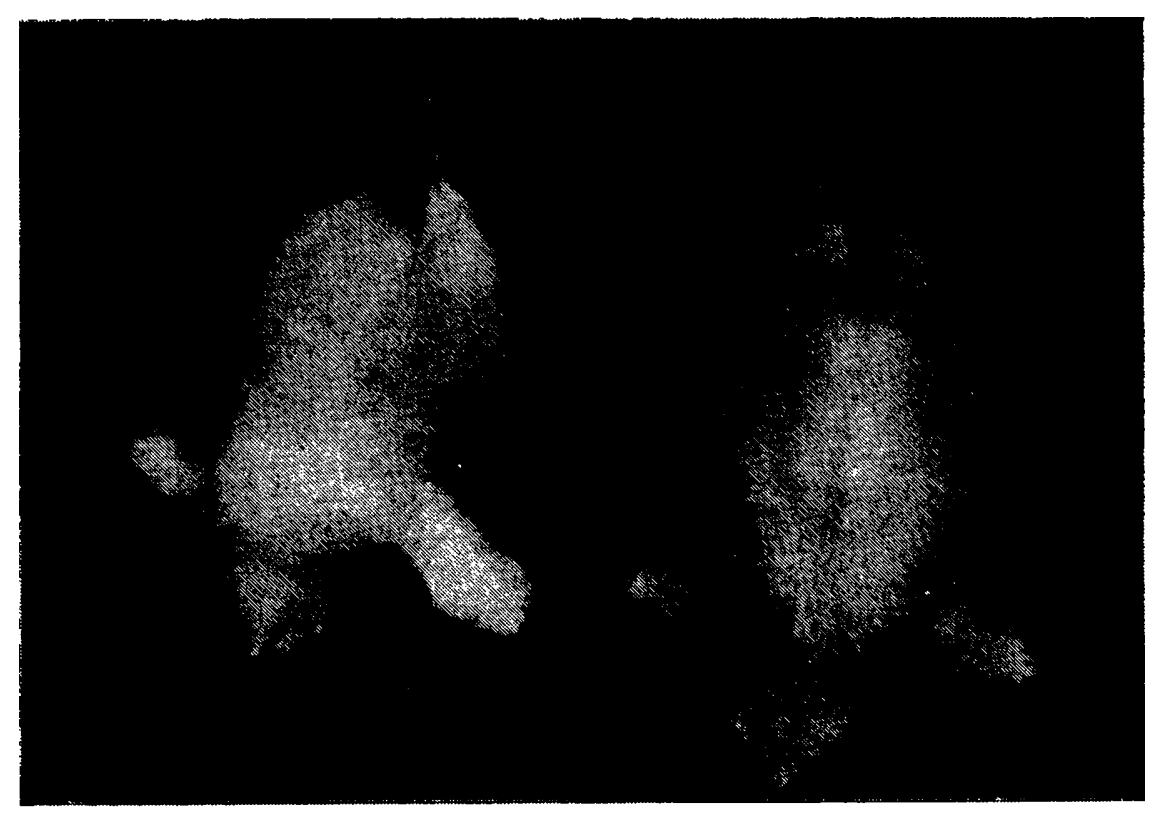

Fig. 7 - A, macho; B, fêmea 